\title{
De reales promesas al olvido concertado: los negros de la Revolución Haitiana en la Nueva Granada
}

\author{
Jorge Victoria Ojeda \\ Archivo Histórico de Mérida, México \\ jorgevictoria40@hotmail.com
}

\section{Resumen}

El artículo aborda un tema poco conocido en la historia de la Revolución Haitiana, tras el conflicto de España con Francia, de 1793 a 1795, en Santo Domingo: en su intento de recuperar el occidente de La Española, la Corona hispana buscó la alianza con los líderes del movimiento de esclavos de la colonia francesa de Saint-Domingue. Con la pérdida de la guerra, los líderes negros fueron desalojados. Las tropas se dividieron en grupos, y uno de ellos fue enviado a Portobelo. Pero al igual que las demás tropas de Auxiliares, las de Portobelo en poco vieron materializadas las promesas de libertad, excepciones, goces y prerrogativas con las cuales el bando español las ganó de su lado.

Palabras clave: esclavos, Revolución Hatiana, Santo Domingo, Auxiliares, Portobelo, Punta Gorda.

\begin{abstract}
The article deals with a little known topic of the Haitian Revolution: after the conflict between Spain and France, 1793 to 1795, the Spanish Crown looked for an alliance with the leaders of the slave movement of the French colony of Saint-Domingue in order to recover the Occidental part of the island. After losing the war, the African leaders had to leave. The troops were divided into groups, and one of them was sent to Portobelo. The Portobelo group, like other auxiliary troops, never saw realized the promises of liberty, exceptions, and prerogatives that the Spanish Crown had made for them.
\end{abstract}

Key words: Slaves, Haitian Revolution, Saint-Domingue, Auxiliaries, Portobelo, Punta Gorda.

\section{Alianza y diáspora de las Tropas Auxiliares de Carlos IV}

Algunos de los protagonistas en los inicios de la revolución haitiana, iniciada en agosto de 1791, han sido relegados al olvido y desaparecido de la historia de ese 


\section{FRONTERAS}

de la historia

levantamiento de esclavos, y ni qué decir entonces de las tropas que comandaban. Esa laguna de información incluye también el papel que esos negros desempeñaron en el episodio de la intervención de España en el conflicto existente en Saint-Domingue, al aliarse con los hispanos, y en el de su historia después de su diáspora por América y Cádiz.

Esa parte omitida de la revolución ha comenzado a ser estudiada por algunos investigadores con el fin de entender mejor el movimiento rebelde y sus asuntos colaterales (Geggus Haitian; Soulodre; Victoria). En estas líneas se aborda el grupo de Auxiliares que, tras la división de la tropa que arribó a La Habana, fue remitido a Portobelo y destinado al sitio de Punta Gorda. En lo general, sus antecedentes ayudan a apreciar la solidez del "proyecto" de revolución y la idea de la libertad general; así como la política de la Corona hispana hacia el conflicto de la parte francesa de la isla y hacia la gente de color, entre otros aspectos. En lo particular, el aporte de esta investigación es conocer otra vía de enriquecimiento y conformación étnica-cultural de los afroamericanos que viven en esa parte de la América Central y el Caribe.

Al iniciarse el levantamiento de esclavos al norte de la caribeña colonia francesa de Saint-Domingue, en la parte occidental de la isla La Española, el cabecilla principal de los negros rebeldes era Boukman. A los pocos meses, al ser asesinado, le sucedieron en la dirección del movimiento Jean François y Georges Biassou, principalmente (Franco 21; James 91, 98). Después de varios fracasos en las peticiones de ayuda a las autoridades hispanas de Santo Domingo, en la sección oriental de la isla, el 22 de febrero de 1793, y en espera de que cuando el mensaje llegase a su destino estuviese declarada la guerra, el monarca español envió una Real Orden a Joaquín García, su gobernador, en la que le mandaba relacionarse con los líderes "Juan Francisco, Biassou, Jacinto" y demás cabecillas, con el fin de tenerlos como aliados. Ordenó además que se dedicasen a atacar y hostilizar a la tropa y a los residentes de la colonia vecina, hasta que la Corona española recuperase la totalidad de La Española ${ }^{1}$. Para tratar de lograr dichas intenciones se mandó a García proveer a los negros de todos los auxilios posibles y prometerles "libertad, goces y prerrogativas" y que el rey los recibiría como súbditos suyos (AGS, SG 7157, exp. 19, núm. 117).

España aprovechó los sucesos que acontecían en la metrópoli francesa y en Saint-Domingue - en ésta existían problemas entre las autoridades coloniales con las de Francia, así como otros de carácter intestino entre los diferentes

\footnotetext{
${ }^{1}$ Los nombres de los jefes negros fueron castellanizados: Juan Francisco, Jorge Biassou y Jacinto.
} 
grupos que constituían la sociedad colonial-, para tratar de lograr sus fines, además de recuperar esa porción territorial que eran las tierras más ricas de Francia en el Caribe (Victoria, Tendencias 40) ${ }^{2}$.

Un asunto que los negros consideraron de importancia, tanto durante aquella relación como en su exilio posterior, fue el de los grados militares que ellos mismos se adjudicaron y que España les respetó de manera tácita mientras los Auxiliares le eran de utilidad para sus fines; posteriormente les fueron negados, aunque varios investigadores opinen lo contrario (Schoelcher 41; Zapatero 289). Sobre el tema, el marqués de Casa Calvo dejaba claro su origen al señalar que los negros "arbitrariamente" se los habían conferido, dejando entrever que el mantenimiento de aquellas designaciones como "Gran Almirante", "Teniente General", "General en Jefe del Ejército" o "Gran Almirante y General de una parte de la Isla de Santo Domingo" por parte de Juan Francisco, y de "Mariscal de Campo" por parte Benjamín, entre otros, "habían sido parte de las contemplaciones hacia los negros para atraerlos". El marqués indicó que aquellas distinciones de los negros causaban problemas al confundirse con las conferidas "dignamente" por el soberano (AGS, $S G$ 7157, exp.19, núm. 136; AGI, $E 5^{\mathrm{a}}$, núm. $23,1^{\mathrm{a}}$ ). Por su parte, Biassou no vacilaba en despachar como: "Caballero del Orden Real y Militar de San Luis, Generalísimo de los Ejércitos de S. M. Católica, Generalísimo de todas las partes conquistadas de Santo Domingo, e Inspector General de los Campos, Arsenales y Fortificaciones de la parte del Norte, conquistada de Santo Domingo" (AGS, SG 7157, exp.4).

También el arzobispo de Santo Domingo dio el visto bueno al reconocimiento de aquellos títulos por parte de las autoridades hispanas, ya que, según el influyente religioso, "todas las distinciones, y títulos brillantes [...] se deshacen con la misma facilidad si conviniere"; además, eran motivo para tener contentos a los líderes rebeldes (AGI, SD 1110).

A su vez, el pretexto por el que los negros justificaron autoasignarse los títulos fue la búsqueda de un mejor desempeño de su seguidores de color, "a redoblar su zelo al servicio de Su Majestad Católica", ya que los Comisarios franceses habían introducido emisarios para atraer a los jefes insurrectos hacia su partido. Apostillaban en su justificación que eran conscientes de que no tenían atribuciones para despachar patentes de esa clase, pero que fue preciso usarlas para atraer, mover e imponer respeto entre los rebeldes, dado que eran "gente

\footnotetext{
${ }^{2}$ Sobre la riqueza de la isla en cuanto a su producción, véase Moreno (31).
} 


\section{FRONTERAS}

de la historia

sin educación, ni sin principios del Arte de la Guerra”, y que si el rey se los exigiese, renunciarían a ellos (AGS, $S G 7157$, exp. 5) ${ }^{3}$.

Esa estructura militar y los grados autonombrados pudieron ser, tal como Vinson opina, una forma de cimarronaje (al menos para los que lo eran) estructurado en jerarquías de tipo militar a semejanza y copia de las que sabían que existían entre los europeos y que a éstos les servía para controlar a la población (241-42). Resulta además interesante la observación de que los rebeldes no incluyesen en su bando alguna referencia a niveles de jerarquía propias de sus grupos tribales africanos.

A pesar de la alianza entre los rebeldes - denominados bajo el pabellón hispano como "Tropas Auxiliares de Carlos IV"-y los españoles y de los éxitos logrados hasta 1794, cuando Toussaint Louverture se pasó al bando francés después de que la Convención francesa se comprometiera a abolir la esclavitud, gran parte de las aspiraciones de ambos aliados se frustraron debido al triunfo de Francia en ese conflicto bélico, derrota que se formalizó en el Tratado de Paz de Basilea, en 1795, con el cual la totalidad de La Española quedó en manos de los vencedores. Francia solicitó entonces a los hispanos la salida de la isla de sus aliados de color que ostentasen algún grado militar por considerar su presencia como un peligro latente para la seguridad (AHN, E 3407) ${ }^{4}$. Ante esa petición, España no tuvo otra opción que depurar a sus Auxiliares, tratando de evacuar únicamente a los principales dirigentes.

García se apresuró a remitir a los Auxiliares a Cuba, a pesar de la negativa de su capitán general y gobernador de La Habana, don Luis de las Casas. Una vez enterado el rey sobre el asunto, decidió dejar a los antiguos aliados en Santo Domingo; pero aún no se enviaban las misivas con sus soberanos deseos a ultramar cuando fue informado por Las Casas de la llegada de las tropas Auxiliares de Juan Francisco al puerto cubano (AGI, E 3, núm. 10).

Poco antes, Las Casas, presionado por el Ayuntamiento y temiendo las posibles repercusiones de la revolución de Saint-Domingue, escribió alarmado a Godoy, secretario de Estado, indicando que la noticia de la próxima llegada de los negros rebeldes había llenado de temor a la población de la ciudad y de toda la isla, debido al posible contagio de sus ideas rebeldes, por lo que no aconsejaba presentarlos "a la vista de un pueblo compuesto en la mayor parte de hombres

\footnotetext{
${ }^{3}$ Sobre el tema, James señala que los negros se apresuraron a investirse con todas las atribuciones y títulos del estamento militar siguiendo las costumbres de los antiguos amos blancos (99).

${ }^{4}$ Sobre los grados militares, su asignación y simbolismo, véase Victoria ("De libertad" 165-69).
} 
de color que viven en la opresión de un número más corto de blancos" (AGI, $E$ $5 \mathrm{~A}$, núm. 22 y $5 \mathrm{~B}$, núm. 176).

El temor del gobernador se fundaba en el rumor de que los cabildos negros de los barrios extramuros de La Habana, que tuvieron noticias del envío de los negros a esa isla antes que las autoridades españolas, se organizaban para celebrar la llegada del general Juan Francisco. El gobernador insistía en que la presencia de aquellos negros en Cuba podría traer funestas consecuencias, como el recelo de los esclavos que viesen en la "insurrección un medio para sacudir tan pesado yugo", tal como había sucedido con la gente de color de Jamaica (AHN, E 3407; AGI, E 5A, núm. 12).

Las autoridades de Cuba se mostraron renuentes a aceptar a esos negros considerados por ellas como sujetos de peligro "por sus ideas de libertad, y por el riesgo de contagio hacia los esclavos de la isla". A su llegada se determinó no mantenerlos en la isla, dividirlos en grupos y remitirlos a Cádiz y a diversas partes del territorio español en América (AGI, E 5B, núm. 176).

García los envió a La Habana en dos viajes, e los cuales el primero fue el de Biassou. Después se depuró el contingente de Juan Francisco, que alcanzó la cifra oficial de 788 individuos, entre hombres, mujeres, adolescentes y niños, aunque en total llegó hasta las 795 personas (AGS, SG 7161, exp. 24; Victoria, "De libertad" 87). Biassou fue mandado a la Florida, acompañado de 23 personas; Juan Francisco fue enviado a Cádiz con familiares y allegados: un total de 136 individuos, y sus tropas fueron fraccionadas y enviadas a Campeche (115 personas), Trujillo (310 Auxiliares) y la isla de Trinidad (144 individuos). A pesar de que en la división no se consideró Portobelo, poco después enviaron allí a 90 sujetos, según listas oficiales (AGS, $S G$ 6824, exp. 15, núm. 252) .

Los factores para la elección de esos sitios fueron su situación marginal, la escasez de esclavos en ellos y su posible utilización en la economía y la defensa (Geggus, "Slavery" 27). Sobre este último punto, las ideas que se habían esparcido en todo el Caribe y tierras continentales del área acerca de los "terribles" sucesos ocasionados por los rebeldes de Saint-Domingue, ocasionaron que su empleo en las armas fuese desestimado como primer factor. Las autoridades buscaron entonces la forma de cumplir lo que el soberano había

\footnotetext{
${ }^{5}$ Como se ha apuntado, las cifras son las oficiales, pero hubo cambios y llegaron a 795 los individuos que salieron de La Habana hacia diferentes regiones. En este ese puerto permanecieron otros tres por enfermedad (Victoria, "De libertad" 302).
} 


\section{FRONTERAS}

de la fistoria

Vol. 12 / 2007

ofrecido a los Auxiliares, y qué mejor si en ese cumplimiento se lograba también algún beneficio económico para la región.

\section{Portobelo: una nueva opción para las tropas de Juan Francisco}

Posteriormente a la división de la tropa y la elección de los destinos adonde enviar a los grupos quedó, según se apunta en los documentos, "un sobrante" de 90 personas $^{6}$. Pero tras haber conferenciado Las Casas con el teniente coronel Rafael de la Luz, gobernador electo de Portobelo, en ese momento de paso por La Habana con dirección a Cartagena de Indias, éste aceptó gustoso aquel "remanente" y señaló que les podría proporcionar algún establecimiento en su futura jurisdicción territorial, por lo que se ordenó a Juan Bautista Ycar, capitán de la fragata María Catalina, que condujese a esos Auxiliares a Portobelo por cuenta de la Real Hacienda (AGN, NE D. 92, ff. 911-911v.) ${ }^{7}$. Para ese punto no se había considerado el envío de Auxiliares debido a que se pensó remitir varias partidas al puerto novohispano de Campeche en las embarcaciones mercantes que para allí saliesen (AMAB, EI 21, 18/177). Con la posibilidad de su envío, y a pesar de su pobreza, insalubridad e incomunicación con otras partes del virreinato de Nueva Granada, las autoridades de Cuba consideraron que los Auxiliares no presentarían problema alguno en esa región de Tierra Firme, servirían para tratar de obtener algún beneficio económico para la región y, a la vez, se libraría a Campeche de recibir - a la fuerza - a más gente de la llamada “indeseable" (AGI, $P$ 292, f. 5v.; AGN, $N E$ D. 92, f. 920; AGS, $S G$ 6824, exp.15, núm. 252).

La salida del grupo de La Habana rumbo a Portobelo fue acompañada por la documentación que avalaba la palabra del soberano hispano de ganarlos a la causa española; otra del 26 de diciembre de 1794 que señalaba la aprobación del rey para la formación en Santo Domingo de dos "Compañías de Emigrados Franceses" conformadas por los negros esclavos que se pasaron al bando hispano; una misiva sobre los sucesos acontecidos en Bayajá por las tropas de Juan Francisco; un documento del 17 de diciembre de 1795 en el que se apuntaban los goces económicos de los jefes de los Auxiliadores a fin de que los datos sirviesen en las posteriores órdenes de subsistencia; por último, la lista de

\footnotetext{
${ }^{6}$ Renée Soulodre también se ha interesado por estudiar este grupo de negros.

${ }^{7}$ En otro documento se apunta que Yzcar los llevaría en la fragata María Rosa, fletada por la Real Hacienda aunque posteriormente se la señala como María Catalina (AGI, P 292, f. 3). En un listado de gente se menciona la embarcación como Mariana Catalina (AGI, C 1475). En ocasiones el apellido de Juan Bautista aparece mencionado como Ycar, y en otras, Yzcar. Utilizamos el que se menciona en primera instancia.
} 
los individuos que pasaban a Portobelo, con sus nombres, edades, actividades y procedencia o "Patria" (AGI, P 292, ff. 1-2v.; AGN, NE D. 92, ff. 903-909).

Juan Bautista Ycar, capitán de la fragata María Catalina y encargado del traslado, recibió 6.000 pesos fuertes de la Tesorería General para la subsistencia en Portobelo de los negros, por lo que debía entregar dicha cantidad a la Real Hacienda tras su arribo. Por su parte, el gobernador de Cuba había retenido 100.000 pesos del situado de Santo Domingo, procedente de Veracruz para

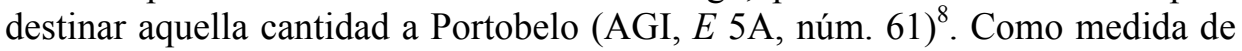
precaución se le otorgaron a Ycar "veinte sables con sus bainas para seguridad de la tripulación", lo que denota el temor existente entre autoridades y capitán de la nave por el eventual amotinamiento de los viajeros de color, ya que éstos viajaban con sus armas desde Santo Domingo. Debido al mal tiempo la nave naufragó cerca de la costa al poco tiempo de zarpar y no se realizó el viaje por entonces (AGI, $P$ 292, f. 16). Poco después, el capitán Antonio Tafiero con el bergantín Carlota se ocupó del asunto (AGN, $N E$ D. 92, f. 922).

\section{La estancia en Chagre y Portobelo}

La lista de los viajeros elaborada el 12 de marzo de 1796 en La Habana señalaba a 90 pasajeros con destino a Portobelo, divididos en 1 oficial, 43 elementos de tropa, 33 mujeres, 9 muchachos y 2 niños de pecho (AGI, $C$ 1475). Sin embargo, el contingente que salió de La Habana el 20 de agosto de 1796 se integró por 86 individuos: 48 hombres, 33 mujeres, 2 menores y 3 niños de pecho. Hubo ligeras variaciones entre las dos cifras, ya que partieron de más cinco hombres, dos niños y un infante de pecho; no se mencionaron los nueve muchachos, algunos de los cuales, quizá, fueron incluidos en la cifra de los hombres. El contingente hizo una breve escala en Campeche, donde desembarcó una mujer de nombre Yanesa y se le otorgó a Tafeiro 400 pesos para habilitarse y seguir su derrotero. A su llegada a la ensenada de Buenaventura, cerca de Chagre, el capitán notificó el desembarco en Campeche y los fallecimientos en la travesía de Yrene y María Luisa, con lo que el total de los pasajeros al arribo debió ser de 83 personas, aunque el informe oficial indicaba 82 (AGI, P 292, ff. $3 \mathrm{v} .-6 \mathrm{v}.)^{9}$.

\footnotetext{
${ }^{8}$ El gobernador García reclamó sin éxito a Las Casas los 100.000 pesos que tomó del situado pretextando que servirían para el envío y mantenimiento de los Auxiliares y emigrados (AGI, $E$ 5B, núm. 83).

${ }^{9}$ Thibaud (110) retoma el error cometido por Jaramillo (27), al señalar que se había mandado a América Central a 780 negros, o sea a toda la tropa que salió de Santo Domingo.
} 


\section{FRONTERAS}

de la historia

Durante la estancia en Chagre llegaron otros negros remitidos por el gobernador de Cuba, primero Silven y las mujeres Franson, Antonia y Meli, y días después arribaron por separado Antonio y Luis Bolf, también desde La Habana. Si los 82 Auxiliares oficialmente llegados, sumados a los seis que lo hicieron con posterioridad a Chagre, dan un total de 88 personas, el recuento de Juan Manuel de Fromiste, ayudante mayor de la Plaza, señaló 85 individuos, incluidos los cuatro que llegaron días después —no contabilizó a los dos últimos-, o sea que, según él, los primeros fueron 81 (AGI, $P$ 292, ff. 9v.-12). La pequeña variación en las cantidades, aunque no se señale, pudo deberse a un mal registro o a fallecimientos.

A causa del mal tiempo para embarcarse, los Auxiliares llegaron a Portobelo por tierra desde Chagre el 16 de febrero de 1797. El informe de su arribo señalaba un total de 85 personas dirigidas por el comandante Sansón, secundado por tres coroneles y un sargento mayor de granaderos. Únicamente al primero se le consideró el grado, ya que era el que se informaba desde Cuba, así como también era el único al que se le otorgaban 15 pesos fuertes al mes como "sueldo" (AGI, P 292, ff. 9v., 11v., 15v. y 23) ${ }^{10}$. Este Auxiliar no aparece en la lista de la plana mayor de Juan Francisco elaborada en diciembre 1795, aunque es posible que se tratase del coronel Sansonci, que comandaba 418 personas en 1794 (AGS, 7157, exp. 58, núm. 298).

La división que se hizo del grupo según su "Patria" señaló a 39 individuos provenientes o indicados como de El Congo, 27 de Guarico apuntados como criollos, 13 mandingas, 3 de Mina, 2 de Calabalí y 1 de Chiria. Entre el número de oficios reportados - a diferencia de los otros contingentes de la dividida tropa donde únicamente se daba la indicación de agricultores, por ejemplo, el remitido al puerto novohispano- estaban: 28 labradores, 4 "servidores", 2 zapateros, 2 peluqueros y 1 los oficios de albañil, cocinero y panadero (AGI, $E$ 24, núm. 53). A Sansón se le indicaba como "cirujano". A ninguna de las mujeres, incluyendo a las solteras, se les apuntó algún oficio ni la edad. La agrupación realizada indica que arribaron 19 familias, con más solteros de ambos sexos (AGI, $P$ 292).

Este listado de los enviados a Portobelo - el más rico en información entre todos los demás de los Auxiliares - indica que la gente proveniente de la región de El Congo fue mayoritaria en su comercio a Sant-Domingue, al contrario de

\footnotetext{
${ }^{10}$ El comandante Sansón es señalado en otro documento con los nombres de Sanzón y Sason (AGN, $N E$ D. 92, ff. 952 y 955).
} 
las otras procedencias mencionadas. Así mismo, llama la atención que la persona de mayor jerarquía, en este caso Sansón, fuese la de mayor nivel en la estructura de ocupación, tal vez en reciprocidad a ello. Esta información sería provechosa trabajarla en conjunto con las listas de los demás grupos y sacar conclusiones más atinadas, asunto que dejaremos para próximos trabajos. Sobre el documento elaborado para la gente para Portobelo, sin duda puede verse como un ejemplo de los lineamientos borbónicos en cuanto a la administración.

Sobre la conformación de los Auxiliares, el gobernador y comandante general de Panamá indicó que se dividieron en dos bandos a partir de la propia separación hecha por ellos: un grupo de los llamados "Congos" y otro denominado "Criollos". En el primero se agrupaba a los negros sin apuntar si eran bozales, nacidos en Santo Domingo o venidos de otras partes de América. En el segundo grupo se incluía a los "no negros", o sea a mulatos casados con negras. Se indica que estos últimos no tenían buenas relaciones con las gentes de los poblados de sus esposas y "hacían rancho separado", pero como eran numéricamente menos, obedecían las órdenes de Sansón y otros autorizados. Apuntaba que las criollas solteras no deseaban casarse con negros, aunque lo hacían al no tener otra opción (AGI, P 292, f. 15v.). Esta división refleja los problemas intestinos en el grupo de Auxiliares, ya sea por su diversa procedencia (unos de África y otros nacidos en América), su ubicación de castas en la jerarquía social para la gente de color y, a la vez, la lucha por "ser" superior a otro sujeto de su misma condición. Esto se traduce también en la poca lealtad de "raza" que pudo existir entre ellos, aunque ante problemas externos sí respondían de manera grupal.

En el padrón elaborado, además del oficio, se asentó la edad de cada individuo varón. A pesar de que esto último pudiese resultar poco fiable, resulta interesante para acercarse a la edad aproximada de esos sujetos. Así, se señala que el comandante Sansón, originario de El Congo y casado con Juana, contaba con 60 años, al igual que otra persona; de más de 50 años había 6 personas; de más de 40, se reportaban 6; sobre los 30 años, había 5; de más de 20 años eran 13 personas, al igual que los de más de 10 años, y de menos de 10 años había 3 (AGI, $P$ 292, ff. 22-23) ${ }^{11}$. Casi la mitad de las personas enviadas eran varones y con una edad que fluctuaba entre los 12 y los 40 años. A pesar de la mención de familias, éstas no eran extensas.

\footnotetext{
${ }^{11}$ Soulodre apunta que en verdad Sansón tenía 30 años y que era soltero (AGN, NEP 3, ff. 555, 559). En nuestra visita al archivo no consultamos ese documento.
} 


\section{FRONTERAS}

de la historia

Con antelación a su arribo, desde el 10 de octubre de 1796, se tomaron algunas medidas ante la llegada de los Auxiliares desde Cuba. En esa fecha se reunieron en Portobelo el gobernador de la Plaza, Rafael de la Luz, y Lorenzo Corbacho, contador oficial de la Real Hacienda, para tratar el asunto. De la Luz mandó preparar los cuarteles desocupados de las baterías de la Plaza para que se alojasen, y que se les destinase a los trabajos de desmontes, "a fin de sacar de dichos Negros algunas ventajas" (AGI, $P$ 292, ff. 4-4v.; AGN, $N E$ D. 92, ff. $915-917 \mathrm{v})$.

Procurando sacar de los negros la utilidad posible en la jurisdicción territorial, así como evitar cualquier incidente que pudiese resultar con los esclavos de los vecinos de la ciudad, se acordó dar a conocer al virrey Ezpeleta las medidas precautorias tomadas. Primero, impedir que "los negros franceses" viviesen en aquella ciudad para evitar el posible contagio de libertad de los esclavos que en ella habitaban, imitando las formas en que los recién llegados la habían conseguido. Segundo, que no era conveniente su establecimiento en forma de pueblo, ya que, además del gasto de la Real Hacienda en la construcción de la iglesia, del cura y demás cosas, la transmisión de su origen a través de padres a hijos no evitaría en lo futuro posibles actitudes sediciosas en el asiento. Tercero, que para hacerles olvidar sus "depravadas máximas" se sugería que se dividiesen en los dos pueblos llamados Palenque y Minas de Santa Rita. El primero se encontraba a diez leguas al este de Portobelo, y el segundo, a seis leguas con dirección oeste; la distancia evitaría contactos entre ellos y ocasionaría la mezcla de los Auxiliares con los pobladores, facilitando el abrazo de la religión católica y el olvido de sus "perniciosas" costumbres. Cuarto, que convenía repoblar ambos pueblos indicados con los negros recién llegados. El de Palenque porque al estar al este de Portobelo se situaba en los límites con los indios "bárbaros" del norte del Darién y reforzarían la postura del pueblo como previsor y defensor de los ataques de los indios; el de Minas de Santa Rita, porque era la única población al oeste de Portobelo y por su situación divisaba ambas costas, y serían de gran ayuda como refuerzos ante cualquier problema que se presentase con el enemigo. Esta fue la primera mención de los Auxiliares como ayuda militar. Quinto, que en esos pueblos existían excelentes tierras de realengo para que trabajasen. Para ello había que dotarlos de chozas, herramientas y animales, tal como se acostumbraba franquear a los nuevos pobladores o colonos. Con estos hechos se buscaba que los recién llegados se interesasen por la población y que lo que obtuviesen en sus tierras se destinase al comercio y al vecindario; así lograrían asegurar su subsistencia y la de sus familias. Sexto, que para poder realizar lo antes expuesto se necesitaba de la ayuda económica de las Reales Cajas de Cartagena, por lo cual la Junta pedía 
que enviasen dicha ayuda lo antes posible en alguna embarcación del rey y que luego ésa se encargase de conducir a los negros a los sitios indicados (AGI, $P$ 292, ff. 4-5v.; AGN, NE D. 92, ff. 916-917v.).

Cuando los Auxiliares arribaron a Portobelo fueron enviados a los cuarteles, se les dio una comida y a cada adulto se le entregaron 20 piezas de jabón, 3 pesos de tabaco en cigarrillos, una botijuela para acarrear agua y 2 pesos de verduras (AGI, $P$ 292, ff. 7v.-8v.; AGN, $N E$ D. 92, ff. 926v.-927). La ayuda económica que se prestó poco después a los Auxiliares consistió en 2 reales diarios, a excepción de los menores de pecho y del comandante Sansón, quien recibió 4 reales, mientras "el virrey pensaba lo que fuese más conveniente" para el grupo. La cantidad desembolsada ascendía a 222 pesos y 3 reales el 28 de febrero, y a finales del mes siguiente la suma había crecido hasta los 676 pesos y 6 reales (AGI, $P$ 292, ff. 9-12) ${ }^{12}$.

Los gastos que ocasionaban los antiguos aliados durante su estancia en Portobelo - alimentación y vestuario - causaban molestias a las Cajas Reales, sobre todo porque los mencionados 6.000 pesos que debían transportarse junto con ellos desde Cuba no llegaban. La Real Contaduría de Portobelo mes a mes lanzaba sus demandas de ayuda económica debido a la escasez de recursos y el aumento de los gastos. A dos meses de su estancia en el puerto se habían erogado en ellos 2.401 pesos y 4,5 reales (AGI, $P$ 292, ff. 12-12v.). Por último, después de muchas cartas de por medio, el conde de Santa Clara, sucesor de Luis de las Casas en el gobierno de Cuba, se desentendió de las peticiones de las Cajas de Portobelo mandando decir al virrey de la Nueva Granada, en septiembre de 1797, que todo socorro necesario se lo solicitase a su homólogo novohispano (AGN, $N E$ D. 92, f. 973v.).

La autoridad de Portobelo procuró vestir "lo más decente" posible la desnudez que presentaban los Auxiliares; para ello se les otorgó una camisa de ruan o crea, un pantalón de listado y un sombrero de paja para los hombres; a las mujeres se les brindó una camisa de ruan, enaguas interiores de lo mismo o de crea y polleras de listado. Al comandante Sansón y a su mujer se les dio una muda a su elección, y a él, una casaca de pana azul y sombrero negro. Asimismo, "aprovechando que algunos tenían conocimientos de sastrería" se les prometió hilo y pita para que elaborasen las ropas para todos ellos (AGI, P 292, ff. 27-27v.; AGN, $N E$ D. 92, ff. 961v.-962) ${ }^{13}$. El ofrecer ese tipo de vestimenta a Sansón constituye una paradoja, pues si por un lado las prendas que se le

\footnotetext{
${ }^{12}$ El año que se apunta en el documento es 1796, lo que constituye un error del copiador.

${ }^{13}$ A pesar de lo señalado, en la lista de oficios de los varones no aparece nadie como sastre.
} 


\section{FRONTERAS}

de la historia

proporcionaron eran para que en lo posible se uniformase a lo militar, por el otro ese rango que decía tener en verdad no se le respetó.

Pero el ofrecimiento de vestuario para los antiguos aliados no sólo fue por razones de solidaridad, sino que, tal como señaló el virrey, por la situación de conflicto con los ingleses y sus aliados zambos convenía que se les "tratase bien a esos negros belicosos", y se debía ser cauteloso en su manejo y tratarlos con comodidad para que estuviesen a gusto (AGI, $P$ 292, ff. 13v.-14). Sin duda la referencia de Saint-Domingue causaba temor como una experiencia negativa de lo sucedido en la antigua colonia francesa, asunto que perduró e incluso se manipuló según los intereses de las élites hispanas (Naranjo 92-96; Thibaud 113-133). A pesar de la idea de utilizar a los negros en la defensa, es difícil que el temor que reinó en primera instancia por su llegada fuese sustituido por la necesidad de medidas de tipo militar, a pesar de la escasez de tropas regulares en el virreinato (cit. en Laviña 172).

\section{Cumpliendo las promesas del rey}

El gobernador de Portobelo señaló al de Panamá, en misiva de febrero de 1797, que la idea general de los Auxiliares era que se les diese un terreno para establecer una población y poder dedicarse a la agricultura, ofreciendo construir sus casas "con hermosura, solidez y comodidades posibles". Añadió que si el gobierno les brindase la ayuda necesaria, los negros decían poder crear un ingenio de azúcar "tan bueno como los mejores del Guarico". De la Luz hizo consideró que si el proyecto era factible no encontraba mejor terreno para ello que Punta Gorda, a cuatro leguas a sotavento de Portobelo, pues ahí existían tierras para explotar, un río que aunque no muy caudaloso sus aguas eran suficientes y su pequeño puerto servía de resguardo para los bongos y canoas que traficaban por el río Chagre, además el terreno no presentaba problemas por las elevaciones naturales. El sitio señalado era propiedad de Ana María de Silva, vecina de Portobelo, y sus dimensiones eran: de este a oeste, tres leguas, marcadas desde el río de Piedra de Punta Gorda hasta uno de sus brazos; de norte a sur, una legua que terminaba en el cerro de Santo Domingo. El terreno se le compraría a la dueña, ya que, según De la Luz, aquella había señalado sus deseos de desprenderse de él (AGI, P 292, f. 14v.; AGN, NE D. 92, ff. 939940).

El informante opinó que fomentar el establecimiento para los Auxiliares no sería de coste alto, ya que las casas "y demás anexos del pueblo" serían levantadas por los mismos negros y únicamente correrían por cuenta de la Real 
Hacienda las herramientas para el corte y elaboración de maderas, además de clavos, cerraduras para puertas y ventanas y el jornal de uno o dos hombres prácticos que les enseñasen y dirigiesen en el corte de los tablones y en el modo de construir las casas. Les darían las herramientas para el trabajo por una sola vez, al igual que los animales y las semillas. Se les ayudaría también con el auxilio de la ración y el vestuario, mientras levantaba la primera cosecha (AGI, $P$ 292, f. 15; AGN, NE D. 92, ff. 940-941).

Por otra parte, el comandante Sansón se presentó ante el gobernador de Portobelo a fines de febrero de 1797 vistiendo divisas de coronel y una cinta encarnada en el ojal de la casaca que portaba. Justificaba el uso de esas prendas diciendo que el rey lo había condecorado con la medalla de su real busto en 1794. Sin embargo, De la Luz le pidió la documentación que avalase ello, pero Sansón indicó que la había perdido en el naufragio ocurrido en las costas de Cuba durante el primer intento de traslado a esa plaza, pero que el marqués de Casa Calvo, antiguo gobernador en Bayajá, podría certificarle su grado. De la Luz indicó que pediría al marqués la documentación respectiva y que mientras tanto se abstuviese de usar otro título más que el de "Comandante" — de rango inferior-, tal como era mencionado en la lista enviada de La Habana; además, el sueldo asignado correspondía a ese grado. La lista enviada de Cuba no señalaba ninguna persona con rango militar aparte de Sansón, por lo que la autoridad no dudó en señalar al líder negro de manera tajante que desconocía los nombramientos que decían tener los otros Auxiliares (AGI, $P$ 292, ff. 15v.16).

En los primeros días de estancia en Portobelo, o mejor, en las afueras, ya que la batería de San Fernando se encontraba frente la ciudad, la vigilancia a que fueron sometidos los Auxiliares reportaba una actitud de "sumisión, gratitud, amor a la Corona española" y al real servicio que estaban seguros que prestarían en la defensa de los territorios del rey. Denotaban, según señaló De la Luz, una racionalidad juiciosa, sobre todo el comandante Sansón, que los controlaba y ellos a la vez lo respetaban. Estas características de mando del negro justificaban la idea del gobernador del puerto de que una vez establecidos en un poblado se les enviase una autoridad que los mandase y observase su comportamiento, tratando en todo momento de eclipsar el mando del mentado Auxiliar (AGI, $P$ 292, ff. 15v.-16; AGN, $N E$ D. 92, f. 942).

Esta persona, además de la capacidad de controlarlos, debía tener conocimientos de agricultura, de construcción de casas y del modo en que se manejan los labradores; a juicio de la autoridad de la plaza, todos esos requisitos los reunía 


\section{FRONTERAS}

de la historia

el capitán de cazadores Manuel Narciso Sanguillén, vecino de Portobelo. El gobernador señaló que los perjuicios que en lo personal se le pudiesen ocasionar a Sanguillén le podrían ser retribuidos posteriormente por la real voluntad. Así mismo, solicitó que se enviase a ese sujeto al poblado en calidad de capitán de guerra, para que fuese más respetado por los nuevos colonos, además de que, tal como aseguró, los mismos Auxiliares estimaban por mejor que una autoridad blanca los mandase y no una de su misma clase (AGI, $P$ 292, ff. 16-16v.; AGN, NE D. 92, f. 942).

En cuanto al sitio de destino, el gobernador de Portobelo escribió al de Panamá apuntando que como carecía de la resolución del virrey, quien a su vez la recibiría del rey, enviaría provisionalmente a los Auxiliares al paraje de Punta Gorda (AGI, $P$ 292, ff. 16v.-17v.; AGN, $N E$ D. 92, f. 943-944).

\section{El poblado de San Carlos de Punta Gorda: destino de los Auxiliares}

La designación de Punta Gorda se debió, entre otras razones, a la fertilidad de sus tierras y porque no representaría mucho gasto a la Real Hacienda. Se pensó que la fundación debería verificarse bajo un plan concertado "y acertadas reglas que se prescriban, ya con arreglo a los conocimientos de la cosa presente", y con atención a la ley (AGI, $P$ 292, ff. 28v.-29).

Pasados algunos meses de estancia, Sansón escribió una carta al gobernador de Portobelo en la que le señalaba su malestar por la situación en que se encontraban en las baterías señaladas, donde incluso se preguntaban si eran esclavos o prisioneros, ya que no se les brindaba lo ofrecido en Santo Domingo (cit. en Soulodre). Tal vez como respuesta a ello, el 27 de julio de 1797 se aprobó la propuesta de la Junta de la Real Hacienda de Portobelo de enviar a los Auxiliares al sitio indicado, continuándose su subsistencia por parte del erario hasta que el poblado pudiese hacerlo de manera autónoma, pero que sus habitantes se mantendrían en los trabajos en que se ocupaban para ese entonces, tratando con ello de bajar el monto de su manutención.

Se mandó que en el paraje destinado levantasen sus casas tomando en consideración las reglas existentes en cuanto a las formas de las edificaciones y en la adjudicación y repartimiento del terreno para labranza particular y ejidos comunes. Si en aquel sitio existiesen tierras realengas, se establecerían en ellas; pero en caso de no existir, se ocuparían las de Ana María de Silva u otro particular, tomándolas en arrendamiento en primera instancia, en censo enfitéutico o en otra forma para que los negros la fuesen pagando poco a poco, 
con lo cual se libraba de esa carga a la Real Hacienda. Para el mejor desarrollo de esa actividad el virrey aceptó la propuesta de que a Sanguillén se le nombrase juez y autoridad del nuevo pueblo, con el título de capitán de guerra (AGI, $P$ 292, ff. 30v.-31; $C$ 1517B).

De inmediato comenzaron las gestiones sobre el terreno pidiendo la Real Contaduría de Portobelo el título de posesión del terreno a Ana María de Silva. Por su parte, Sanguillén debía pasar al paraje de Punta Gorda para verificar sus características y la inexistencia de tierras realengas cercanas. En el sitio comprobó la existencia de tierras fértiles en el paraje y la extensión de éstas, maderas, bejucos, cañas, etc., todo lo necesario para la construcción y mantenimiento del poblado. Al mismo tiempo, informó de la inexistencia de tierras de la Corona en las inmediaciones y que los vecinos de los nuevos colonos serían, por el brazo del río, Félix de Contreras, y Bernardino Delgado por el lado del río Grande (AGN, $N E$ D. 92, f. 977-979).

El nombre elegido para el lugar por la Junta de Hacienda realizada en octubre de 1797 fue el de San Carlos de Punta Gorda "que deberá [ser] del agrado de Su Majestad [Carlos IV] en memoria y agradecimiento de las piedades que dispensa [...] a estos nuevos colonos". Sanguillén debía salir con veinte de los Auxiliares y con Justo del Valle y Juan José Noriega, los milicianos del cuerpo de cazadores, con el fin de levantar dos galerías o barracones para albergar a los futuros habitantes. Para realizar esas tareas debería pasar a los Almacenes Reales para recoger los utensilios necesarios: un hacha y un machete para cada uno de los remitidos con Sanguillén, seis picos y dos piedras de moler, incluyendo el reemplazo de las que se inutilizasen. Posteriormente se les darían herramientas a los que pasasen a tomar posesión del terreno y emprender la labranza (AGN, $N E$ D. 92, f. 979-980).

La idea de la eventual separación de los negros fue desechada, ya que el 14 de abril de 1798 Sanguillén informó a la Real Hacienda que el nuevo establecimiento de Punta Gorda contaba ya con dos galerías para el alojamiento de todos los Auxiliares, las tierras habían sido limpiadas y quemadas para la siembra de maíz, plátanos, arroz y otros frutos que se comenzaron a plantar. Así mismo, estaba listo el terreno donde se levantaría la población luego de que concluyesen las siembras. El informante agregó que los negros estaban contentos con el sitio y con su dedicación a la agricultura, y que con el tiempo el poblado sería de gran ventaja para los suministros de frutos a Portobelo (AGN, NE D. 92, ff. 982-982v.). 


\section{FRONTERAS}

de la historia

No obstante lo ya realizado en el establecimiento, la Real Hacienda no dejaba de llamar la atención sobre las erogaciones que ello ocasionaba y el posible traslado de los Auxiliares a otro pueblo ya establecido, con intención de evitar más gastos en un asiento provisional, sobre todo si aquellos 6.000 pesos provenientes de La Habana para su manutención estaban ya olvidados. A pesar de la eventual idea de traslado, con el informe de Sanguillén en mano la Junta de Hacienda esperaba que en un lapso de ocho a diez meses el socorro diario que recibían los Auxiliares podía suspenderse, ya que sus cosechas podrían proporcionarles la subsistencia. Agregaba que de los 72 pobladores de Punta Gorda - los restantes a la suma original debieron de fallecer o salir del grupo, pues no hay mención de ellos-, ninguno quería dejar el sitio y que para ese momento, según la Junta, ya habían olvidado sus "máximas antiguas" y, lejos de ser perjudiciales, convenía que se estableciesen en la Provincia porque con sus labores ayudarían "a remediar las necesidades que continuamente se experimentan en esta Plaza de arroz, maíz, pescado, carbón y leña".

De igual manera, las embarcaciones pequeñas, como bongos, piraguas y canoas del tráfico, lograrían algún beneficio con esas mercancías, además de que podían protegerse en el pequeño puerto por alguna eventualidad. En todo caso, el informe de la Junta no olvidó señalar que con el cambio de poblado "podrían resultar malas consecuencias". En julio de 1798 las arcas reales de la provincia informaron al gobernador de Panamá que las siembras del poblado estaban ya concluidas y esperaban órdenes sobre "dar principio o no a la población pues estamos en el caso de no perder tiempo en ello para que no resulten perjuicios a la Real Hacienda" (AGN, NE D. 92, f. 983v.-985).

El 20 de octubre de 1798 el virrey de Nueva Granada dio su visto bueno para la conformación de poblado de negros en Punta Gorda en calidad de perpetuo, apuntando la consideración de una restricción en los gastos que se tuviesen que erogar. Al año siguiente, en Real Cédula del 15 de agosto de 1799, el rey aprobó las medidas tomadas por su virrey de ultramar, recomendando estar a la mira de la conducta de las familias de los Auxiliares, su porte y ventajas en el establecimiento, y evitando en lo posible gastos a la Real Hacienda. Un mes después se mandó que pasasen al poblado diez hombres con la obligación de observar las operaciones de los negros y evitar el más leve desorden (AGN, NE D. 92, f. 979, 987-994).

El fin del estatus provisional del sitio de Punta Gorda, que no esperó la orden del soberano como se anunciaba en las misivas que Las Casas remitió a las autoridades de las regiones adonde se envió a los Auxiliares, fue dado por el 
virrey, y se oficializó enviando a un religioso misionero del Colegio de Propaganda Fide de Panamá. El elegido para la misión fue el padre Antonio Ynchaurdieta, que falleció en agosto de 1801 y fue reemplazado dos años después por el fraile Fernando Ayuso, del mismo Colegio (AGI, P 294, exp.26) $)^{14}$.

Jaén, en un estudio realizado sobre la marginalidad rural en Panamá durante el siglo XVIII, aborda los casos de Palenque, Santa Rita y Punta Gorda, todos con población de origen africano, y concluye que los tres poblados muestran estructuras de comunidades marginales, pero Punta Gorda fue el que en menor tiempo fue cayendo en la marginación rural. Esto pone en duda la posible ayuda económica que se buscaba que prestase a la región de Portobelo. Como posible causa de ello, Jaén señala que los Auxiliares fueron insertados a una nueva vida cualitativamente inferior a la que habían conocido en Santo Domingo (363366). No concordamos con Jaén sobre este punto. Sí por "Santo Domingo" quiso decir Saint-Domingue, es obvio que las condiciones en Punta Gorda no podían ser peores que en las plantaciones esclavistas; así mismo, si hace referencia a la situación cuando luchaban en el bando español en el Santo Domingo hispano, durante ese tiempo los hombres no se dedicaron más que a actividades de la guerra y las mujeres a la subsistencia alimentaria de la familia. Son tres situaciones distintas, una para cada etapa diferente, y sin duda, ninguna tan negativa como la primera.

\section{Un repaso a su historia, ¿se cumplieron los sueños?}

El envío de una partida de las Tropas Auxiliares de Juan Francisco a Portobelo fue circunstancial debido a la fortuita presencia del gobernador electo de esa plaza en La Habana cuando procedía de España rumbo a Cartagena de Indias. Ante la premura por deshacerse de los Auxiliares, las autoridades habaneras propusieron a Rafael de la Luz la remisión de 90 Auxiliares a la región del istmo centroamericano, en vez de esperar que por medio de varias remesas aquel "sobrante" de las tropas pudiese ser enviado a Campeche. El viaje de los negros a Portobelo en los primeros meses de 1796 se vio interrumpido por las adversidades y tuvieron que retornar a La Habana, de donde salieron de nueva cuenta el 20 de agosto siguiente. Llegaron a Portobelo después de más de un

\footnotetext{
${ }^{14}$ A pesar de lo asentado en el documento, Soulodre apunta información proveniente del AGN (CO 2, ff. 941-982), de donde retoma que el primer religioso encargado del pueblo fue el misionero capuchino Atanasio Baldigna, quien falleció en noviembre de 1801, y que posteriormente a las autoridades les fue difícil encontrar algún religioso que estuviese dispuesto a ir a Punta Gorda. En el texto de la investigadora no se menciona a los dos religiosos que citamos.
} 


\section{FRONTERAS}

de la historia

año de espera en el puerto habanero desde que salieron de Bayajá recluidos en la embarcación y luego de pasar por Chagre.

La idea de remitir a ese grupo a Portobelo fue aceptada por la autoridad electa debido al estado de pobreza económica de la región en ese entonces. Con esa circunstancia como antecedente, los Auxiliares de Santo Domingo no representarían problema alguno por posibles levantamientos y podrían ser utilizados en la agricultura y en la defensa, dado el corto número de efectivos existente para ello y los eventuales problemas que se podían suscitar con los indígenas y zambos por los costados de tierra y con los extranjeros por el mar.

Las autoridades de Portobelo y Panamá, sin embargo, vieron en los recién llegados una oportunidad para mejorar en lo posible la economía de la zona, sobre todo en lo referente al abasto de géneros del campo para el primer puerto, cuya dependencia de Cartagena y de otros sitios era mayúscula. Pensaron también utilizarlos para la defensa, pero los informes sobre su actuación en Santo Domingo creaban recelos. Se pensó evitar su contacto con los negros esclavos de la región e impedir que influyesen en ellos. No en balde las autoridades señalaron su temor a un contagio de nuevas ideas ilustradas provenientes de la revolución francesa, de la que los negros, según ellas, estaban imbuidos.

Ante los gastos que ocasionaban los Auxiliares, las autoridades pusieron interés en remitirlos a un poblado para que empezasen a trabajar la tierra, pagando con su trabajo lo erogado por la Real Hacienda, y que en un futuro cercano fuesen autosuficientes y ayudasen en el abastecimiento de Portobelo.

Por otra parte, el grupo dirigido por el comandante Sansón, único sujeto con algún grado militar, solicitó un terreno para establecerse y dedicarse a la agricultura. En ningún momento hicieron alusión a desempeñarse en la milicia, incluso esos negros se decían buenos agricultores y capaces de desarrollar un ingenio azucarero como los mejores del Guarico.

El hecho de haber sido enviados únicamente al mando de un comandante, el no querer desempeñarse en la milicia, la generalizada juventud de los miembros del grupo y sin familia muchos de ellos, son rasgos que señalan que este grupo de Auxiliares debió ser considerado, tal como lo escribieron las autoridades de Cuba, "un sobrante" que quedó después de que los principales líderes separasen a sus familiares, allegados y demás. No contamos con algún dato que apunte cómo se dio la división en La Habana, aunque era de esperarse que las 
autoridades la hicieran según sus intereses; sin embargo, que los principales jefes de color hayan salido a sus destinos con sus familias y allegados es indicador de que influyeron en la forma en que se formaron los diversos contingentes.

Por otra parte, tal como sucedió con los enviados a Trujillo, es relevante el hecho de que a los negros se les permitiese llevar consigo sus fusiles, a pesar de considerarlos sujetos peligrosos, debido quizá a unos de los goces o prerrogativas prometidos. No se señala el número total de personas que viajaban en la embarcación que los condujo a Chagre, pero si unos 30 negros - contando sólo a los mayores de 20 años - tenían fusiles y la autoridad otorgó 20 sables al capitán para la seguridad de la tripulación, seguramente había muchos más españoles a bordo.

Sobre sus habilidades, de los oficios registrados en el grupo de 85 personas que oficialmente llegaron a Portobelo, el de "labrador" fue el más numeroso: 28 sujetos. Otros oficios que se indicaban eran los de albañil, panadero, peluquero y cocinero, tareas que implican su desempeño en poblados, lo que apunta que este grupo de Auxiliares no se conformó únicamente por los alzados trabajadores del campo, sino también de otras personas simpatizantes del movimiento que vivieron en las poblaciones de Saint-Domingue.

La división por "Patria" reporta un alto porcentaje de gente de El Congo y mandingas, además de otras procedencias africanas, lo que apoya la idea de que el grupo era en general joven, o sea era gente nacida en África y posteriormente trasladada a la colonia francesa.

Las razones económicas llevaron a elegir al sitio de Punta Gorda primero como asiento provisional y después definitivo para los 72 Auxiliares registrados en 1798. El abastecimiento del cual las autoridades hacían mención para la tan asolada región les llevó a olvidar los puntos uno y dos expuestos en las consideraciones de don Rafael de la Luz y don Lorenzo de Corbacho en octubre de 1796. En el primero se decía impedir que los negros viviesen en la ciudad, pero a pesar de otras opciones de sitios más lejanos a aquélla, se eligió el más cercano, precisamente para poder abastecer de manera más fácil a Portobelo. El segundo punto obviado fue el que aconsejaba que no viviesen todos juntos en un mismo poblado, pues temían las posibles sediciones y los gastos de la Real Hacienda en la construcción de la iglesia y mantenimiento del cura, entre otros. Pero las autoridades, a pesar de la idea de separarlos, decidieron sacar un mejor beneficio en la unión de todos para el trabajo, aprovechando que la mayoría de 


\section{FRONTERAS}

de la historia

los negros eran jóvenes. Tal debió ser el interés de las autoridades para que se estableciesen en Punta Gorda, que el terreno, aunque no se sabe si fue vendido, se pensó en arrendarlo a su propietaria por medio de la cesión por dominio público.

Además, la división entre el grupo ya estaba marcada por ellos mismos: por una parte los criollos y por otra los negros africanos; entonces al gobernador le quedó únicamente establecer una autoridad que supiese controlar al grupo $-\mathrm{O}$ grupos- de la mejor manera y en beneficio del gobierno español, sin inmiscuirse en los conflictos intestinos de los Auxiliares. Por su parte, los Auxiliares vieron en la autoridad enviada a su interlocutora ante el gobierno hispano para tratar asuntos de su relación con él.

Convencidas las autoridades de Portobelo de que los negros habían olvidado en unos cuantos meses "sus máximas antiguas" y que no representaban problema alguno para la región, fueron dotados de tierras para la labranza. Ésta no fue trabajada de manera comunal, sino que, tal vez debido a su misma división interna, el reparto individual fue considerado la mejor opción, mientras que la siembra y la cosecha fueron elegidas y controladas por las autoridades hispanas. Aunque desconocemos los resultados, tal vez al poco éxito del proyecto se debiese su pronta marginación, ya que, como los negros señalaban, únicamente sabían trabajar los géneros de Saint-Domingue (caña de azúcar, cacao, algodón).

Por último, de las reales promesas, los Auxiliares enviados a Portobelo obtuvieron por un tiempo ciertos goces económicos y facilidades para instalarse en Punta Gorda. Sin embargo, lo otorgado fue por interés de las autoridades que buscaron recibir a cambio una retribución en la economía, tal como se pensó en La Habana ante la disyuntiva de qué hacer con esos buscados aliados, convertidos después de la guerra en incómodos ex Auxiliares. Con el paso del tiempo su historia se fue perdiendo quizá por un olvido premeditado por parte de las autoridades.

\section{Bibliografía}

\section{Fuentes primarias}

Archivo General de Indias, Sevilla, España (AGI):

Estado (E) 3, 5a, 5B, 24, 52. 
Santo Domingo (SD) 1110.

Panamá (P) 292, 294,

Cuba (C) 1475, 1517B.

Archivo General de la Nación, Bogotá, Colombia (AGN):

Negros y Esclavos (NE) D. 92.

Negros y Esclavos de Panamá (NEP) 2 y 3.

Archivo Histórico Nacional, Madrid, España (AHN):

Estado (E) 3407.

Archivo General de Simancas, España (AGS):

Secretaría de Guerra 6824, 7161, 7157.

Archivo Museo Álvaro Bazán, Madrid, España:

Exp. a Indias (EI) 21.

\section{Fuentes secundarias}

Franco, José Luciano. Revoluciones y conflictos internacionales en el Caribe, 1789-1854. La Habana: Academia de Ciencias de Cuba, 1965.

Geggus, David. "Slavery, War, and Revolution in the Greater Caribbean, 17891815". A turbulent time. The French revolution and the Greater Caribbean. Eds. David Gaspar y David Geggus. Indiana: Indiana University Press, 1997. 1-50.

-. Haitian Revolutionary Studies. Bloomington; Indianápolis: Indiana University Press, 2002.

Jaén Suárez, Omar. La población del istmo de Panamá: Estudio geohistórico.

Madrid: Agencia Española de Cooperación Iberoamericana, 1998. 


\section{FRONTERAS}

de la historia

Vol. $12 / 2007$

James, C. L. R. Los jacobinos negros. Toussaint L'Ouverture y la Revolución de Haití. Madrid: Turner; Fondo de Cultura Económica, 2003.

Jaramillo, Jaime. "Esclavos y señores en la sociedad colombiana del siglo XVIII". Ensayos de historia social. Obras completas de Jaime Jaramillo Uribe. Bogotá: Ceso, 2001. 3-62.

Laviña, Javier. "Ilustración y reacción en Nueva Granada". Boletín Americanista 41 (1991): 165-78.

Moreno Franginals, Manuel. El ingenio: complejo económico social cubano del azúcar. Madrid: Crítica, 2001.

Naranjo Orovio, Consuelo. "La amenaza haitiana, un miedo interesado: Poder y fomento de la población blanca en Cuba". El rumor de Haití en Cuba: Temor, raza y rebeldia, 1789-1844, González R. et al. Madrid: Consejo Superior de Investigaciones Científicas, 2004. 83-178.

Soulodre-La France, Renée. "[i]Viva Dios y el Rey de España por quien muero contento! 'French Africans' in the Spanish Caribbean". Ponencia. $52^{\circ}$ Congreso Internacional de Americanistas, Sevilla. 17-21 julio 2006.

Schoelcher, Víctor. Vie de Toussaint Louverture. París: Karthala, 1982.

Thibaud, Clément. "Coupé têtes, brûle cazes. Temores y deseos de Haití en el Caribe hispánico". Visiones y revisiones de la Independencia americana. México, Centroamérica y Haití. Eds. Izáskun Álvarez y Julio Sánchez. Salamanca: Universidad de Salamanca, 2005. 107-33.

Victoria Ojeda, Jorge. Tendencias monárquicas en la revolución haitiana. El negro Juan Francisco Petecou bajo las banderas francesa y española. México: Siglo XXI; Universidad de Quintana Roo.

—. "De 'libertad, excepciones, goces y prerrogativas'. Impulso y dispersión de las Tropas Auxiliares del rey de España en la guerra de Santo Domingo (1793-1848)". Trabajo de grado de doctorado. Universitat Jaume I., 2005.

Vinson, Ben. "Las compañías milicianas de pardos y morenos en la Nueva España. Un aporte para su estudio". Población y estructura urbana en 
México, siglos XVIII y XIX. Comps. Carmen Blázquez Domínguez, Carlos Contreras Cruz y Sonia Pérez Toledo. Jalapa: Instituto MoraUniversidad Veracruzana, 1996. 239-50.

Zapatero, Manuel. La guerra en el Caribe en el siglo XVIII. Madrid: Servicio Histórico Militar, Museo del Ejército, 1990.

Fecha de recepción: 24 de noviembre de 2006.

Fecha de aprobación: 30 de julio de 2007. 